\title{
Using Virtual Reality to promote pre-service teachers' classroom management skills and teacher resilience: A qualitative evaluation
}

\section{Jolien M. Mouw ${ }^{1}$, Marjon Fokkens-Bruinsma ${ }^{2}$, Gert-Jan Verheij ${ }^{3}$}

${ }^{1}$ Department of Educational Sciences, University of Groningen, the Netherlands, ${ }^{2}$ Department of Teacher Education, University of Groningen, the Netherlands, ${ }^{3}$ Center for Information Technology, University of Groningen, the Netherlands.

\begin{abstract}
Many novice teachers have difficulties with selecting and applying effective classroom management strategies to prevent or diminish disruptive behaviors. Negative experiences with classroom management largely determine teacher wellbeing and early attrition. Therefore, more in-training opportunities are needed to prepare prospective teachers to manage complex classroom practices effectively. A Virtual-Reality environment seems promising in developing classroom management skills (CMS) and promoting teacher resilience; however, students' and educators' perceptions towards this technology influence its potential. This study describes four pre-service teachers' and six school-based teacher educators' experiences with and perceptions towards the use of a Virtual Reality learning environment to train classroom management skills and promote teacher resilience. Responses of semi-structured interviews reflect five themes: software- and equipmentrelated issues; feedback cues; realism and authenticity; instructor proficiency; and added value for teacher training. Results show that, for most themes, preservice teachers and school-based teacher educators raised similar remarks and/or suggestions for improvement; however, they differed in their perceptions towards the added value of Virtual Reality to teacher training curricula. Our study highlights teachers' needs for highly authentic and realistic simulations aligned with real-life classrooms and presents recommendations to augment the immersive experience needed for teachers to develop effective CMS and become more resilient.
\end{abstract}

Keywords: Virtual Reality; Teacher training; Classroom management; Resilience; Qualitative evaluation. 


\section{Introduction}

Classroom management refers to all measures a teacher takes in establishing a positive and orderly working and learning environment in which effective social and academic learning can occur (Korpershoek, Harms, De Boer, Van Kuijk, \& Doolaard, 2016). Effective classroom management entails restoring order by recognizing disruptive behaviors and application of effective classroom management strategies (CMS) aimed at preventing, changing, or disciplining disruptive behaviors; understanding the effect of classroom management strategies on specific behaviors; and teachers' beliefs in their ability to effectively implement classroom strategies (i.e., teacher-efficacy; Tschannen-Moran \& Woolfolk-Hoy, 2001). However, selecting and applying effective CMS is one of the foremost concerns in everyday teaching practice and many pre-service and beginning teachers experience difficulties in deciding between preventive (e.g., making eye contact with students) or reactive (e.g., disciplining) strategies when addressing specific behaviors (Korpershoek et al., 2016; Lane, Menzies, Bruhn, \& Crnobori, 2011; Putman, 2009), often resulting in a downwards spiral reinforcing disruptive behaviors. Negative experiences with disruptive behaviors and classroom management and low levels of teacher-efficacy are key factors in both teachers' wellbeing and attrition (Brown \& Wynn, 2007).

Many pre-service teachers feel that their internship does not provide sufficient opportunities for practicing and developing effective classroom management strategies, as experimenting with CMS to understand what works in which situations could negatively impact the teacherstudent relationship (Van Tartwijk, Mainhard, Brekelmans, Den Brok, \& Levy, 2014). Even if teachers only once retort to less effective CMS, the negative consequences for the teacherstudent interpersonal relationship could last throughout the academic year. Such a disturbed interpersonal relationship could result in lower levels of teacher self-efficacy, wellbeing, and even attrition. Moreover, pre-service teachers' field experiences are often confined to specific days and/or parsed in a relatively short period in which only a limited amount of disruptive behaviors can be observed and managed, leaving little room for putting different CMS into practice. Therefore, it is essential to provide our future teachers with more in-training opportunities to develop more (varied) CMS and fine-tune their strategies. An alternative to real world, in-vivo training is simulation, for example by means of Virtual Reality (VR).

Lugrin and colleagues (2016) designed a VR-environment in which prospective secondaryschool teachers can train their classroom management skills. Such an interactive VRenvironment has several advantages as compared to other methods frequently used to promote classroom management skills. The immersive experience simulated by the HeadMounted Display creates a realistic and authentic learning environment (Burdea \& Coiffet, 2003 ) in which pre-service teachers can interact with students and respond to a variety of pre-programmed disruptive behaviors ranging in complexity levels. This enables practicing with many more (different) disruptive behaviors and CMS as compared to in-vivo 
internships. More importantly, it is possible to rerun complex situations multiple times and experience the reciprocal relationship between specific behaviors and different CMS without compromising the teacher-student interpersonal relationship. Using a VR-environment to practice and develop effective classroom management skills could also positively affect teacher wellbeing, and, more specifically, teacher resilience. Resilience can be conceptualized in terms of experiencing positive emotions, self-confidence, and being able to make realistic judgments regarding self-efficacy, interpersonal skills, and behavioral management. We assume that being able to practice a variation CMS in response to many different disruptive behaviors will likely to benefit these aspects, resulting in more resilient teachers who are committed, engaged, and motivated to improve their teaching and to remain in the profession (Mansfield, Beltman, Broadley, \& Weatherby-Fell, 2016).

The first evaluation of the developed VR-environment seems promising in terms of essential usability requirements, the effect of feedback cues, and technology acceptance (Lugrin et al., 2016). However, little is known of how pre-service teachers actually perceive and experience such a VR-learning environment in terms of its potential as an in-training opportunity for developing their CMS. As successful implementation of educational innovations stands or falls with students' and educators' perceptions towards new technologies (Schneckenberg, 2009), we conducted a study to evaluate pre-service teachers' experiences with and perceptions towards the use of a Virtual Reality learning environment to train classroom management skills and promote teacher resilience.

\section{Methods}

\subsection{Participants and Design}

In the period between December 2018 and April 2019, we invited two groups of users to test the classroom management VR-learning environment (Lugrin et al., 2016) and participate in a follow-up interview. The first group consisted of four pre-service teachers (one man, three women) as the goal was to evaluate their perceptions towards and experiences with a VRlearning environment to promote CMS and teacher resilience. In addition, we included six school-based teacher educators (three men, three women) in our evaluation, given that classroom management training is often considered as 'too disconnected from everyday classroom practices' (Putman, 2009). Therefore, school-based teachers' experiences and perspectives on the degree of transfer to real-life educational situations as simulated by the VR-environment are highly relevant when evaluating the potential of learning environments aiming to prepare prospective teachers for their future profession. 


\subsection{Procedure}

Participants were invited (in pairs or small groups) to our university's VR-center to test two aspects of Lugrin et al.'s VR-module; the classroom simulation itself and the instructor control dashboard (Figure 1; see Lugrin et al., 2016, p. 7, for a detailed description). The VRexperience was followed by a semi-structured interview. Questions were partially based on the work of Lugrin et al. (2016) and tapped into participants' overall impressions, simulation/user experiences, possible drawbacks, and opportunities or potentials of using VR to support pre-service teachers' development of CMS and resilience.
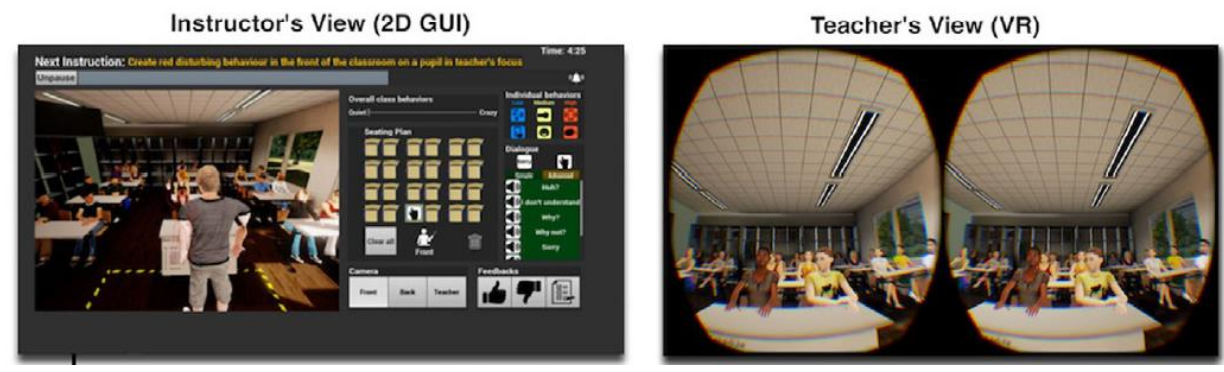

Figure 1. Instructor control dashboard (l) and VR-simulation (r). Source: Lugrin et al. (2016).

\subsection{Method of Analysis}

All notes taken during the interviews were digitalized. We followed a Grounded Theory approach as we first established sensitizing concepts guiding further in-depth thematic analysis and exploration of our data (Braun \& Clarke, 2006).

\section{Results}

Participants' responses were categorized into five emergent themes: (1) software- and equipment-related issues; (2) feedback cues; (3) realism and authenticity; (4) instructor proficiency; and (5) added value for teacher training. In the following subsections, we will discuss each of the themes in more detail.

\subsection{Software- and Equipment-Related Issues}

All participants reported bugs and system-glitches that lowered the experienced level of immersion. For example, they mentioned that not all student avatars were visible or responded to the teacher, that some of the disruptive behaviors did not work after activation, and delays in visualization after adjusting the controls. Some of the optional classroom layouts did not enable realistic in-class movement as participants could walk through walls or desks. Participants tended to trip over the cable connecting the Head-Mounted Display to the computer. Pre-service teachers explicitly vocalized the need for a 'software pre-training', 
for example, regarding the use of the handhelds, picking up objects, and how to navigate through the virtual classroom. In addition, informing them in advance, on what the VRenvironment looks like, would help set more realistic expectations.

\subsection{Feedback Cues}

The appropriate use and timing of the feedback cues was not clear for all participants. As one pre-service teacher stated: "How do you use the feedback cues?" This could stem from the fact that we did not yet run specific scenarios/scripts in our exploration-phase, thus, there was no need to provide specific feedback. In addition, participants deemed the audio signal of the feedback cues as "rather awkward and disconnected from everyday classroom practices", which raised debate on the added value of the feedback cues in its current form. Others indicated that a more diverse range of feedback cues could be conducive to the learning experience, especially when more targeted and/or specific feedback on CMS (instead of signaling wrong or right) could be given.

\subsection{Instructor Proficiency}

Participants from both groups thought instructor skills regarding controlling the interface are essential for establishing effective learning processes. Many participants felt that the instructor him/herself should be highly proficient in CMS, or at least should know which strategies are most effective given a certain behavior, to facilitate effective feedback. One pre-service teacher struggled with aptly fulfilling the instructor-role and mentioned it was rather difficult to having to respond immediately by selecting appropriate student behaviors after observing their peers implementing classroom strategies. Moreover, when multiple avatars displayed disruptive behaviors, it was not always clear whom the teacher addresses. Enabling the possibility to name the students would be helpful, as would presenting the instructor with a live feed of all sounds and conversation occurring in the virtual classroom.

\subsection{Realism and Authenticity}

Our participants generally held positive perceptions of the experienced levels of realism and authenticity. As one school-based teacher educator mentions: "the feeling of being in the classroom is real". However, they do feel some improvements could (and should) be made. For example, one student indicated that the visual experience is highly similar to being in a classroom, but that the software lacks realism when it comes to simulating an authentic auditory experience (availability and display of noises/sounds). Others stress this observation and felt that the current version could be improved as only noises and sounds related to grouplevel disruptive behaviors are available. Integrating noises exemplifying both individuallevel disruptive and non-disruptive behaviors, and background noises (e.g., 'buzz') in the software is thought to be essential in simulating a realistic an authentic classroom. Another way of increasing transfer to real-life classrooms is to reconceptualize the classification and 
visualization of behaviors. For example, pre-service teachers mentioned that in real life, some of the simulated 'bad' behaviors such as punching a neighbor could be considered as playful or friendly behaviors. Behaviors that in everyday classrooms would be considered as highly disruptive (such as kicking and punching), were not that well visible in the simulation, suggesting a milder categorization. Several participants mentioned a lack of common movements as wiggling and stretching (i.e., non- disruptive behaviors). Pre-service teachers and school-based teacher educators thought that naming student avatars, enabling a variety of emotional (facial) expressions, and exploring the possibility of programming avatarspecific characters (e.g., behavioral patterns) enhances realism and authenticity. Almost all participants mentioned that the pre-programmed verbal responses of student avatars impeded immersion. More complex interaction patterns, preferably supported with accurate lip movement, are needed. One school-based teacher educator mentioned: "It would be nice if it would be possible to take phones from student avatars physically", as this is a valid response in real-life situations. Similarly, being able to relocate students after displaying disruptive behaviors is recommended.

\subsection{Added Value for Teacher Training}

The pre-service teachers were rather positive about the whole experience and see its potential for training classroom management skills and promoting teacher resilience. Some endorse the added value in the current teacher-training curriculum as they see possibilities for using the VR-software in the context of microteaching (in which pre-service teachers practice with parts of a lesson such as attaining focus when starting a lesson). The pre-service teachers also indicated that the VR-simulation primes all sorts of emotions (for example, when students start jumping on their chairs) that can also be experienced when teaching everydayclassrooms. Another added value for the teacher-training curriculum could be realized by integrating pre-service teacher's PowerPoint or Digi board slides in the VR-classroom as this would enable purposeful content-related practices.

The school-based teacher educators had mixed feelings about the VR-experience, as their perceptions vary from "finding it fantastic", to not being able to see how the application could be used in the near future. School-based teacher educators felt that purposeful integration and implementation in the teacher-training curriculum is impeded by a lack of verbal interaction and the system's and instructor's inability to respond to non-verbal CMS. Especially experienced teachers are highly skilled in effectively using non-verbal CMS; strategies that were not always recognized by the instructor (who tried to figure out how to increase disruptive behaviors instead of observing the teacher wearing the VR-headset). 


\section{Discussion and Directions for Future Use}

We aimed to evaluate pre-service teachers' and school-based teacher educators' experiences with and perceptions towards the use of a Virtual Reality learning environment to train CMS and promote teacher resilience. Five themes emerged from the semi-structured interview data. Participants in both groups felt that software-and equipment-related issues lowered the experienced immersion, and pre-service teachers explicitly mentioned the need for a software pre-training. Our participants felt that the non-specific and unrealistically sounding feedback cues are not conducive to learning and welcome the possibility of giving targeted feedback. Both groups of participants thought instructor proficiency is a two-fold issue. First, for VRnovices, the instructor control dashboard was not intuitive. Second, similar to real-life practice (Ryan \& Cooper, 2004), effective CMS can only develop under supervision of an experienced CMS-proficient teacher giving targeted feedback. Both groups hold relatively similar perceptions of realism and authenticity. Most of them thought the visual simulation was highly realistic and authentic, but that the auditory experience could and should be improved as real-life classrooms burst with life. Another essential aspect in which the VRenvironment differs from real classrooms is the lack of human-like complex interaction. Last, both groups of participants mentioned that the classification, modelling, and visualization of behaviors should be reconceptualized to facilitate transfer to real-life classrooms. Schoolbased teacher educators and pre-service teachers differed in the perceived added value of VR for teacher education. Pre-service teachers were unanimously positive regarding the intraining possibilities of using VR to develop CMS and promote teacher resilience, whereas school-based teacher educators' perceptions varied largely. Most were cautious regarding its potential for implementation in teacher education, mostly due the lack of human-like interaction, suggesting that even a realistic, immersive experience in a virtual reality can be 'too disconnected from everyday classroom practice' (Putman, 2009).

Overall, based on our participants' observations, it can be concluded that a VR-environment for training CMS has untapped potential as there are various ways to improve the immersive experience and transfer to real-life classrooms. Therefore, our first recommendation is to improve the module based on our participants' suggestions to increase the level of realism and authenticity and augment the immersive experience prerequisite for purposeful implementation in teacher education. Our second recommendation is to provide meaningful behavioral scenarios simulating complex classroom situations as every-day teaching practices are highly susceptible to micro-level influences. For example, it would be informative for prospective teachers to engage in a scenario in which disruptive behaviors gradually build up if the teacher does not immediately and effectively address (emerging) disruptive behaviors. Or a situation in which many different behaviors occur simultaneously and need immediate orchestration (for example, when a teacher wants to start his/her lesson while some students are talking to each other, others are engaged with their cell phone, and 
some even are asleep). Third, we recommend exploring possibilities for providing authentic, less intrusive, and targeted feedback on specific CMS, for example by integrating just-intime voice coaching in the software. Last, we recommend examining the degree to which VR-supported in-training opportunities have a long-term impact, for example by monitoring beginning teachers' resilience and CMS. This project is the first step in an ongoing exploration of the potential of using VR to support teachers' development of CMS, selfefficacy, resilience, and wellbeing, and we are looking forward to taking the next step in our research and Virtually Realize our participants' recommendations!

\section{References}

Braun, V., \& Clarke, V. (2006). Using thematic analysis in psychology. Qualitative Research in Psychology, 3(2), 77-101. doi:10.1191/1478088706qp063oa.

Brown, K. M., \& Wynn, S. R. (2007). Teacher retention issues: How some principals are supporting and keeping new teachers. Journal of School Leadership, 17(6), 664-698. doi:10.1177/105268460701700601.

Burdea, G., \& Coiffet, P. (2003). Virtual reality technology (2nd ed.). Hoboken, NJ: Wiley.

Korpershoek, H., Harms, T., De Boer, H., Van Kuijk, M., \& Doolaard, S. (2016). Meta-analysis of the effects of classroom management strategies and classroom management programs on students' academic, behavioral, emotional, and motivational outcomes. Review of Educational Research, 86(3), 643-680. doi:10.3102/0034654315626799.

Lane, K. L., Menzies, H. M., Bruhn, A. L., \& Crnobori, M. (2011). Managing challenging behaviors in schools. Research-based strategies that work. New York, NY: The Guilford Press.

Lugrin, J.-L., Latoschik, M. E., Habel, M., Roth, D., Seufert, C., \& Grafe, S. (2016). Breaking bad behaviors: A new tool for learning classroom management using Virtual Reality. Frontiers in ICT, 3, 1-21. doi:10.3389/fict.2016.00026.

Mansfield, C., Beltman, S., Broadley, T., \& Weatherby-Fell, N. L. (2016). Building resilience in teacher education: An evidenced informed framework. Teaching and Teacher Education, 54, 77-87. doi:10.1016/j.tate.2015.11.016.

Putman, S. M. (2009). Grappling with classroom management: The orientations of preservice teachers and impact of student teaching. The Teacher Educator, 44(4), 232-247. doi:10.1080/08878730903180226.

Ryan, K. \& Cooper, J. M. (2004). Those who can, teach (10th ed.) Boston, MA: Houghton Mifflin.

Schneckenberg, D. (2009). Understanding the real barriers to technology-enhanced innovation in higher education. Educational Research, 51(4), 411-424. doi:10.1080/00131880903354741

Tschannen-Moran, M., \& Woolfolk-Hoy, A. (2001). Teacher efficacy: Capturing an elusive construct. Teaching and Teacher Education, 17(7), 783-805. doi:10.1016/S0742051X(01)00036-1.

Van Tartwijk, J., Mainhard, T., Brekelmans, M., Den Brok, P., \& Levy, J. (2014). Docentleerling interacties en het sociaal klimaat in de klas. In J. van Tartwijk, M. Brekelmans, P. den Brok \& T. Mainhard (Eds.), Theorie en praktijk van leren en de leraar (pp. 25-42). Amsterdam: SWP. 